\title{
Dejeto líquido de suínos: I - perdas de nitrogênio e fósforo na solução escoada na superfície do solo, sob plantio direto
}

\author{
Pig slurry: I - nitrogen and phosphorus losses by surface run off \\ in a soil cropped under no tillage
}

\author{
Carlos Alberto Ceretta $^{1}$ Claudir José Basso ${ }^{2}$ Frederico Costa Beber Vieira $^{3}$ \\ Miguel Gustavo Herbes ${ }^{4}$ Isabel Cristina Lopes Moreira ${ }^{5}$ Alexandre Léo Berwanger ${ }^{5}$
}

\section{RESUMO}

A aplicação de dejeto líquido de suínos em áreas de lavoura e/ou pastagem representa a adição de nutrientes às plantas e também uma alternativa de reciclagem. Contudo, as perdas de nitrogênio e fósforo por escoamento superficial no plantio direto, podem diminuir sua eficiência à nutrição de plantas e representar um poluente potencial, comprometendo a qualidade da água no ambiente. Esse trabalho teve por objetivo avaliar a importância do escoamento superficial às perdas de nitrogênio e fósforo aplicados via dejeto líquido de suínos. O trabalho foi conduzido na Universidade Federal de Santa Maria, RS, no período de maio de 2000 a maio de 2002 em Argissolo Vermelho Arênico distrófico. Numa rotação aveia preta/milho/ nabo forrageiro, foram estudadas as doses de 0, 20, 40 e 80 $\mathrm{m}^{3} \mathrm{ha}^{-1}$ de dejetos líquidos de suínos, distribuídas a lanço sobre a superfície antes da semeadura de cada espécie da rotação. As concentrações de fósforo disponível e nitrogênio mineral na solução escoada na superfície do solo, foram diretamente relacionados com as doses de dejeto aplicadas. As concentrações de nitrogênio e fósforo na solução escoada na superfície do solo, bem como a predominância de amônio ou nitrato, estão diretamente relacionadas ao intervalo entre a aplicação do dejeto e o primeiro escoamento superficial. As perdas de nitrogênio e fósforo por escoamento superficial, expressas em $\mathrm{kg} \mathrm{ha}^{-1}$, são pequenas, porém as maiores concentrações observadas nos picos de perdas preocupam com relação à possibilidade de eutroficação de mananciais de água.
Palavras-chave: esterco, resíduos orgânicos, adubação orgânica, dejetos de animais.

\begin{abstract}
The application of pig slurry in crop land and/ or pasture areas, besides being an additional source of nutrients to plants is also an alternative for manure disposal. However, nitrogen and phosphorus losses by surface run off in no tillage can decrease the efficiency of organic fertilizers and also be a potential pollutant, threatening the quality of water bodies. This work aimed at evaluating the importance of surface run off as a nitrogen and phosphorus loss phenomenon applied via pig slurry. The work was carried out at the Federal University of Santa Maria, RS, from May, 2002, in a Typic Hapludalf soil. Black oat (Avena strigosa), corn (Zea mays) and oilseed radish (Raphanus sativus), in a succession were fertilized with increasing doses of pig slurry $\left(0,20,40\right.$ and $\left.80 \mathrm{~m}^{3} \mathrm{ha}^{-1}\right)$. The pig slurry was distributed on soil surface before the sowing of each species of the succession for two consecutive years. The concentrations of reative phosphorus and mineral nitrogen concentrations in the surface run off water were directly related to the doses of applied pig slurry. Phosphorus and nitrogen concentrations in the surface run off solution as well as the predominance of ammonium or nitrate are directly related to the interval between the waste application and the first superficial flow, with in turn depended on the rainfall event. Nitrogen and phosphorus losses by superficial flow, expressed in $\mathrm{kg} \mathrm{ha}^{-1}$, are small,
\end{abstract}

${ }^{1}$ Departamento de Solos, UFSM, 97105-900, Santa Maria, RS, Brasil. E-mail: ceretta@ccr.ufsm.br

${ }^{2}$ SLC Agrícola, Brasil. E-mail: bassopp@slcagricola.com.br

${ }^{3}$ Universidade Federal do Rio Grande do Sul (UFRGS), RS, Brasil. E-mail: fredericocbv@bol.com.br

${ }^{4}$ Weisul Agrícola Ltda, Brasil. E-mail:miguel.fzcn@weisul.com.br

${ }^{5}$ Universidade Federal de Santa Maria, Santa Maria, RS, Brasil. E-mail: isabellm@mail.ufsm.br 
but their concentrations at some periods are high enough to cause concerns of eutrophication of water bodies.

Key words: manure, crop residue, organic fertilizer, animal waste.

\section{INTRODUÇÃO}

A aplicação de dejetos de suínos no solo é uma forma de ciclar e disponibilizar nutrientes às plantas. Contudo, pode haver escoamento superficial, seja pelas altas quantidades aplicadas, somadas a relevos acidentados, ou mesmo pela ocorrência de precipitações pluviais em solos com pouca cobertura e baixa permeabilidade. Por isso, quantidades significativas de constituintes de dejetos de suínos, como nitrogênio e fósforo podem ser perdidos por escoamento superficial, tanto que YOUNG \& MUTCHLER (1976) e STEENHUIS et al. (1981) constataram perdas de N de 25 a 50\% após aplicação do dejeto e ocorrência de chuvas pesadas e sucessivas. Contudo, as quantidades de nutrientes perdidos dependem diretamente das doses de dejeto aplicadas, bem como diminuem com as chuvas subseqüentes (EDWARDS \& DANIEL, 1993).

As perdas de fósforo solúvel podem ser altas e causar eutroficação mesmo em sistemas conservacionistas, onde a erosão é diminuída sensivelmente (YLI-HALLA et al., 1995). Do ponto de vista ambiental, concentrações de fósforo inorgânico na água de superfície de 0,1 a $0,2 \mathrm{mg} \mathrm{L}^{-1}$ são consideradas críticas (SHARPLEY et al., 1996). Entretanto, esses baixos teores de fósforo são menores do que os considerados como ideais na solução do solo para um bom crescimento de plantas, ou seja, de 0,2 a $0,3 \mathrm{mg} \mathrm{L}^{-1}$ (HEATHWAITE et al., 2000) e mostra a alta susceptibilidade à contaminação por fósforo na água. Por outro lado, é importante observar os resultados de BERTOL et al. (2004), os quais mostram que em preparos conservacionistas, como é o caso do plantio direto, as concentrações de nutrientes e carbono orgânico são maiores do que em sistemas com revolvimento de solo mas que as perdas totais ocorrem de forma inversa.

O trabalho teve por objetivo avaliar a importância do escoamento superficial como fenômeno de perdas de nitrogênio e fósforo aplicados via dejeto líquido de suínos, utilizandose uma área cultivada com a rotação aveia preta/ milho/nabo forrageiro, durante dois anos, sob plantio direto.

\section{MATERIAL E MÉTODOS}

O experimento foi conduzido no período de maio de 2000 a maio de 2002 num Argissolo Vermelho distrófico arênico, na Universidade Federal de Santa Maria, RS, com declividade média de $4 \%$ e há oito anos sob plantio direto. Do horizonte Ap ao Bt do Argissolo Vermelho distrófico arênico, os teores de argila variaram de 170 a $290 \mathrm{~g} \mathrm{~kg}^{-1}$, de silte de 300 a $370 \mathrm{~g} \mathrm{~kg}^{-1}$ e de areia total (incluindo fina e grossa) de 340 a $530 \mathrm{~g} \mathrm{~kg}^{-1}$. Características químicas (0 a 10cm) eram: argila $240 \mathrm{~g} \mathrm{~kg}^{-1}$, pH (água) 4,7, M.O. $16 \mathrm{~g} \mathrm{dm}^{-3}$, P 15,0mg dm ${ }^{-3}$ K 96,0mg dm ${ }^{-3}$, Al, Ca e Mg 0,8, 2,7 e $1,1 \mathrm{cmol}_{\mathrm{c}} \mathrm{dm}^{-3}$, respectivamente.

Durante dois anos foram aplicadas a lanço 0, 20, 40 e $80 \mathrm{~m}^{3}$ ha $^{-1}$ de dejeto líquido de suínos de esterqueira (Tabela 1), antes da semeadura de cada cultura na rotação aveia preta (Avena strigosa Schieb), milho (Zea mays) e nabo forrageiro (Raphanus sativus), totalizando três aplicações anuais. No florescimento da aveia preta e do nabo forrageiro era feita a dessecação, distribuição do dejeto e implantação da próxima cultura na mesma área. O delineamento experimental foi em blocos ao acaso com quatro repetições. O escoamento superficial foi avaliado utilizando-se, em cada parcela de $14 \mathrm{~m}^{2}$, uma armação metálica com $0,75 \mathrm{~m}$ de comprimento e $0,50 \mathrm{~m}$ de largura, com uma calha coletora conectada com mangueira a um recipiente de armazenamento de 23 litros (detalhes em BASSO (2003)). Nas determinações das concentrações de $\mathrm{N}$ mineral na solução escoada utilizou-se a metodologia descrita em TEDESCO et al. (1995). Na solução escoada foi avaliado o P reativo (ortofosfato inorgânico) adicionando-se $\mathrm{HCl}$ 0,11mol $\mathrm{L}^{-1}$ (TEDESCO et al., 1995) e posteriormente o P foi determinado por colorimetria, conforme metodologia descrita em MURPHY \& RILEY (1962). No primeiro ano, estas mesmas metodologias foram utilizadas para determinar as concentrações de $\mathrm{N}$ total e $\mathrm{P}$ total. Os intervalos entre as coletas foram determinados pelos eventos de precipitações pluviais capazes de gerar escoado. Detalhes de todas as precipitações, datas de implantação das culturas, coletas dos escoados existem em BASSO (2003).

A falta de “independência” entre as observações ao longo do período de avaliação inviabiliza uma análise de regressão. Além disso, a impossibilidade de se controlar experimentalmente algumas variáveis tais como volume e intervalo das precipitações, implica na não satisfação de todos os pressupostos da análise de variância. Por isso, optou-se nesse estudo em apresentar as médias com seus respectivos desvios padrões. 
Tabela 1 - Características do dejeto líquido de suínos aplicado antes da implantação de cada espécie da rotação aveia preta/milho/nabo forrageiro nos dois anos agrícolas.

\begin{tabular}{|c|c|c|c|c|c|c|c|c|c|c|c|c|}
\hline \multirow{2}{*}{$\begin{array}{c}\text { Características do } \\
\text { dejeto }\end{array}$} & \multicolumn{12}{|c|}{ Antes da implantação de cada cultivo } \\
\hline & \multicolumn{4}{|c|}{ Aveia preta } & \multicolumn{4}{|c|}{ Milho } & \multicolumn{4}{|c|}{ Nabo forrageiro } \\
\hline & \multicolumn{12}{|c|}{ Ano agrícola (2000/2001) } \\
\hline pH (água) & & & 7,2 & & & & 6,6 & & & & 7,5 & \\
\hline \multirow[t]{2}{*}{ \% matéria seca } & & & 1,9 & & & & 9,9 & & & & 0,8 & \\
\hline & \multicolumn{12}{|c|}{ Aplicação - kg ha-1 } \\
\hline Dose $-m^{3} h a^{-1}$ & $\%$ & 20 & 40 & 80 & $\%$ & 20 & 40 & 80 & $\%$ & 20 & 40 & 80 \\
\hline N-total ${ }^{(1)}$ & 0,11 & 22 & 44 & 88 & 0,75 & 151 & 301 & 602 & 0,14 & 28 & 56 & 112 \\
\hline \multirow[t]{2}{*}{ P-total ${ }^{(2)}$} & 2,40 & 9 & 18 & 36 & 2,10 & 42 & 84 & 168 & 4,10 & 3,4 & 6,8 & 13,6 \\
\hline & \multicolumn{12}{|c|}{ Ano agrícola (2001/2002) } \\
\hline pH (água) & & & 6,8 & & & & 7,8 & & & & 8,2 & \\
\hline \% matéria seca & & & 1,1 & & & & 3,7 & & & & 1,2 & \\
\hline \multirow[t]{2}{*}{$\%$ N-total ${ }^{(2)}$} & & & 3,5 & & & & 2,7 & & & & 3,1 & \\
\hline & \multicolumn{12}{|c|}{ Aplicação - kg ha ${ }^{-1}$} \\
\hline Dose $-\mathrm{m}^{3} \mathrm{ha}^{-1}$ & $\%$ & 20 & 40 & 80 & $\%$ & 20 & 40 & 80 & $\%$ & 20 & 40 & 80 \\
\hline N-total ${ }^{(1)}$ & 0,08 & 16 & 32 & 64 & 0,20 & 40 & 80 & 160 & 0,18 & 36 & 72 & 144 \\
\hline P-total ${ }^{(2)}$ & 1,50 & 3,3 & 6,6 & 13,2 & 1,60 & 12 & 24 & 48 & 1,30 & 3,1 & 6,2 & 12,4 \\
\hline
\end{tabular}

(1) (2) Análise e cálculos em base úmida e seca, respectivamente.

\section{RESULTADOS E DISCUSSÃO}

A concentração de $\mathrm{N}-\mathrm{NH}_{4}^{+}$na solução escoada na superfície do solo, no primeiro ano de cultivo de aveia preta e aos 19 dias da aplicação do dejeto, foi relativamente baixa não sendo possível a sua determinação a partir desse dia (Figura 1a). Esse período é muito próximo ao obtido por ALMEIDA (2000), a qual observou que o processo de nitrificação ocorreu 20 dias após a aplicação do dejeto, o que justifica o incremento nas concentrações de $\mathrm{N}-\mathrm{NO}_{3}{ }^{-}$a partir do décimo oitavo dia da aplicação. Após 41 dias da aplicação do dejeto no primeiro ano de cultivo da aveia preta, não foi detectado $\mathrm{N}-\mathrm{NH}_{4}{ }^{+}$e $\mathrm{N}^{-} \mathrm{NO}_{3}{ }^{-}$na solução escoada, o que, possivelmente, esteja associado ao baixo teor de matéria seca do dejeto aplicado e, por conseqüência, baixos teores de $\mathrm{N}$ total (Tabela 1), além de outras perdas por volatilização, percolação e a absorção pelas plantas.

No segundo ano de cultivo da aveia preta, onde o primeiro evento (chuva capaz de gerar escoamento superficial) ocorreu 11 dias após a aplicação do dejeto, já houve predomínio do $\mathrm{N}-\mathrm{NO}_{3}$ sobre a concentração de $\mathrm{N}-\mathrm{NH}_{4}{ }^{+}$na solução escoada na superfície do solo (Figura 2ab). Logo, levando-se em consideração que os dejetos aplicados antes da semeadura da aveia preta nos dois anos de cultivo, apresentaram características semelhantes (Tabela 1), a forma predominante de $\mathrm{N}-\mathrm{NH}_{4}{ }^{+}$ou $\mathrm{N}-\mathrm{NO}_{3}{ }^{-}$na solução escoada na superfície do solo depende do intervalo entre a aplicação do dejeto e o primeiro escoamento superficial, havendo uma tendência dessas concentrações de $\mathrm{N}-\mathrm{NH}_{4}{ }^{+}$prevalecerem sobre

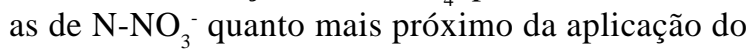
dejeto ocorrer o escoamento.

Ao contrário do observado no segundo ano de cultivo da aveia preta, no primeiro ano de cultivo do milho, quando foi aplicado um dejeto com aproximadamente $10 \%$ de matéria seca, considerado muito alto, as concentrações de $\mathrm{N}_{-} \mathrm{NH}_{4}{ }^{+}$no primeiro escoamento superficial foram elevadas (Figura $1 \mathrm{~cd}$ ). Isso ocorreu 12 dias após aplicação do dejeto e atingiu 20, 39 e $86 \mathrm{mg} \mathrm{L}^{-1}$ para as doses de 20, 40 e $80 \mathrm{~m}^{3} \mathrm{ha}^{-1}$, respectivamente. Esses valores foram maiores do que os observados para o $\mathrm{N}-\mathrm{NO}_{3}{ }^{-}$, que passaram a predominar somente a partir de 29 dias após a aplicação do dejeto, atingindo seu pico máximo e somente para a dose de $80 \mathrm{~m}^{3} \mathrm{ha}^{-1}$, aos 57 dias após a aplicação do dejeto (Figura 1d).

O maior período de tempo observado para a completa nitrificação do $\mathrm{N}-\mathrm{NH}_{4}{ }^{+}$do dejeto, no primeiro ano de cultivo do milho, além do maior teor de matéria seca, menor contato com o solo, também pode estar associado ao tempo de adaptação dos microrganismos responsáveis pelo processo de nitrificação a esse novo substrato. Essa foi a justificativa para o incremento no intervalo de tempo entre a aplicação do dejeto e os maiores picos de perdas de nitrogênio por volatilização, apresentada no trabalho de SØRENSEN (1998). A justificativa para 
(a)

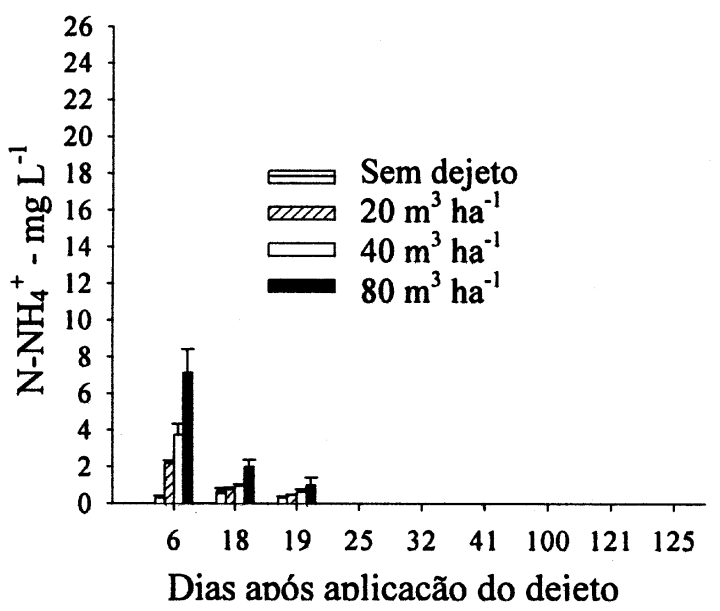

(c)

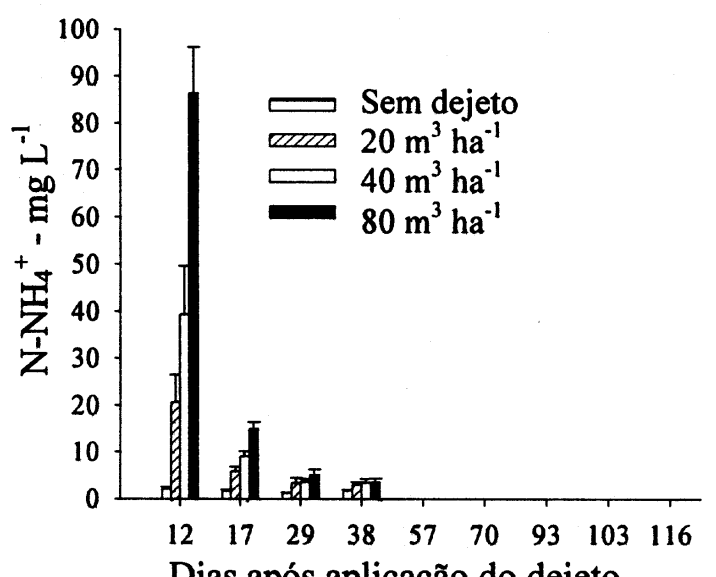

Dias após aplicação do dejeto

(e)

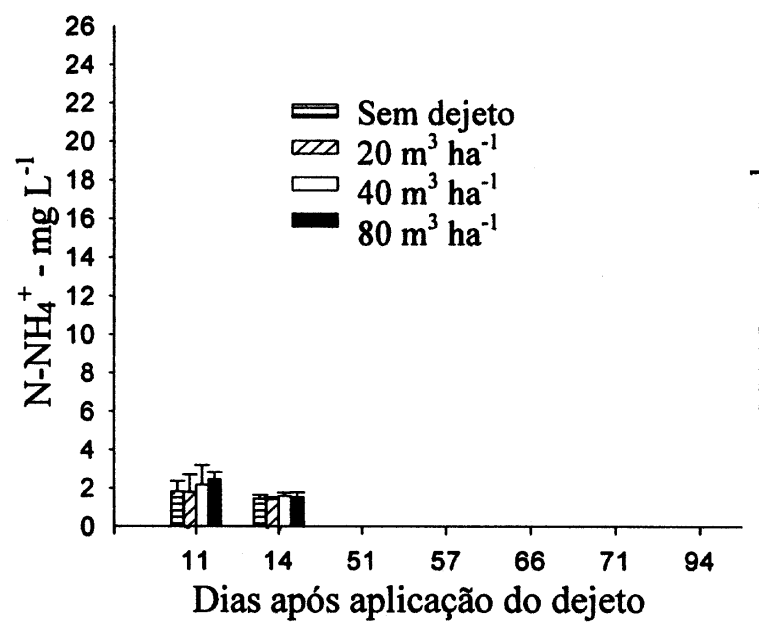

(b)

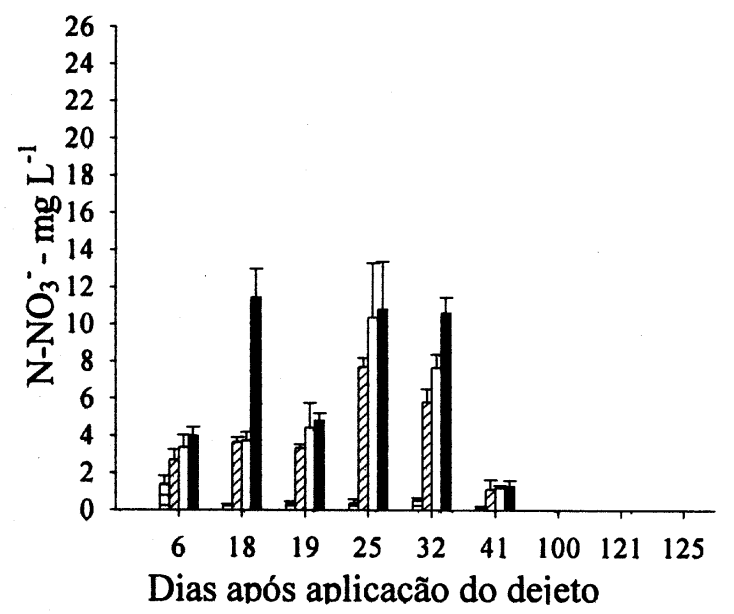

(d)

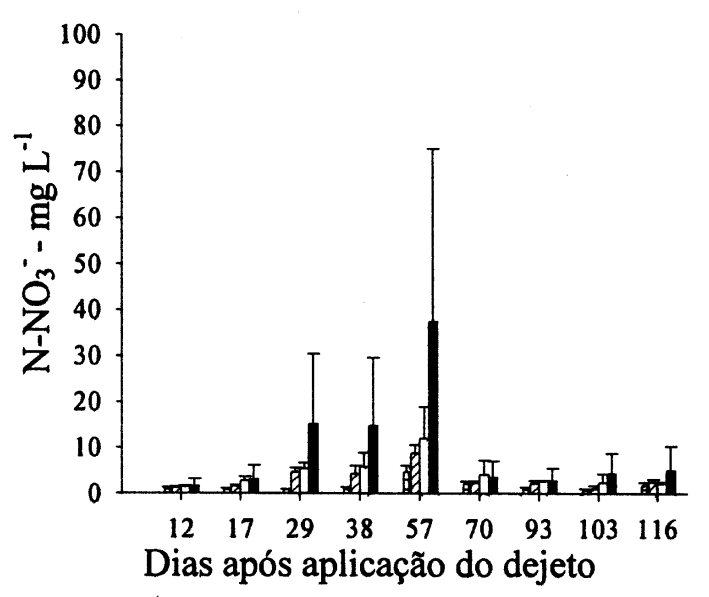

(f)

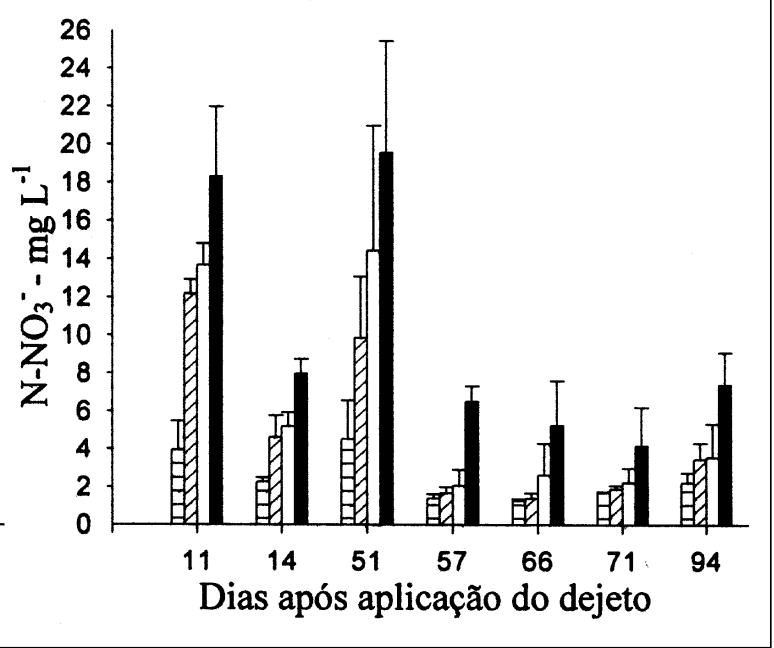

Figura 1 - Concentração de $\mathrm{N}\left(\mathrm{N}_{-} \mathrm{NH}_{4}^{+}\right.$e $\left.\mathrm{N}-\mathrm{NO}_{3}^{-}\right)$na solução escoada na superfície do solo durante o cultivo da aveia preta no primeiro ano (a) e (b), do milho (c) e (d) e nabo forrageiro (e) e (f), respectivamente, com aplicação de dejeto líquido de suínos.

Ciência Rural, v.35, n.6, nov-dez, 2005. 
(a)

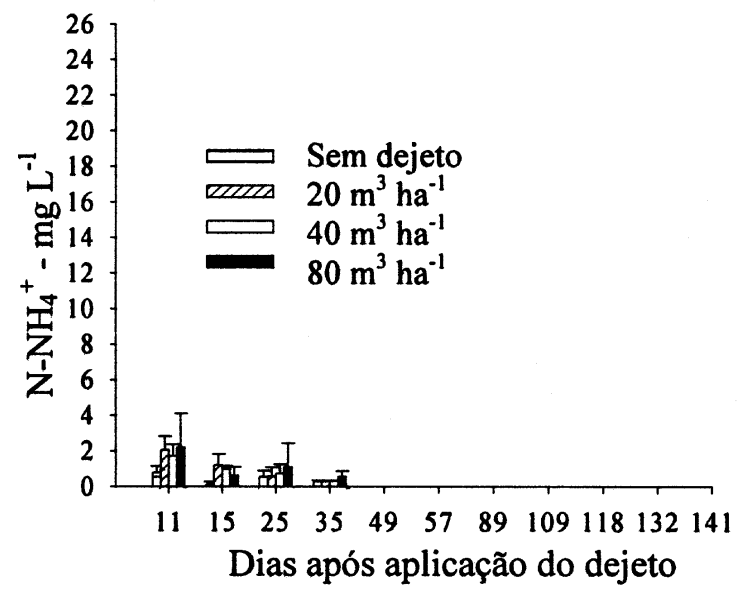

(c)

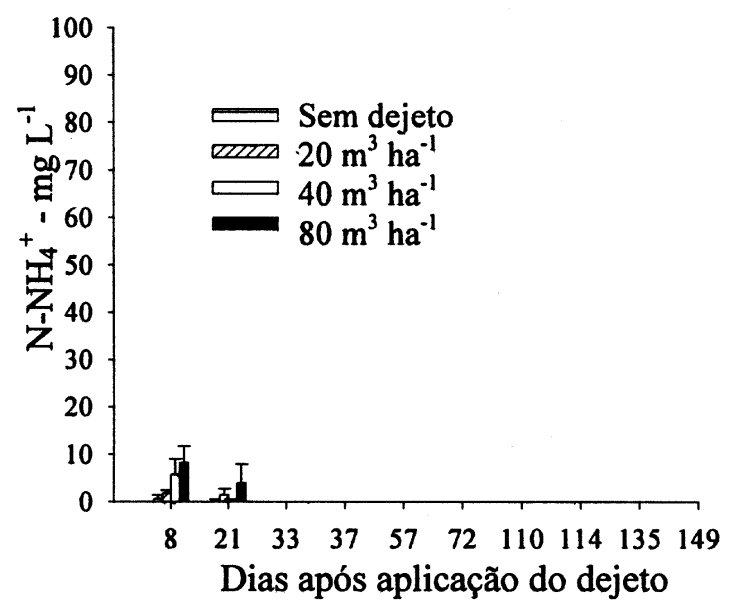

(e)

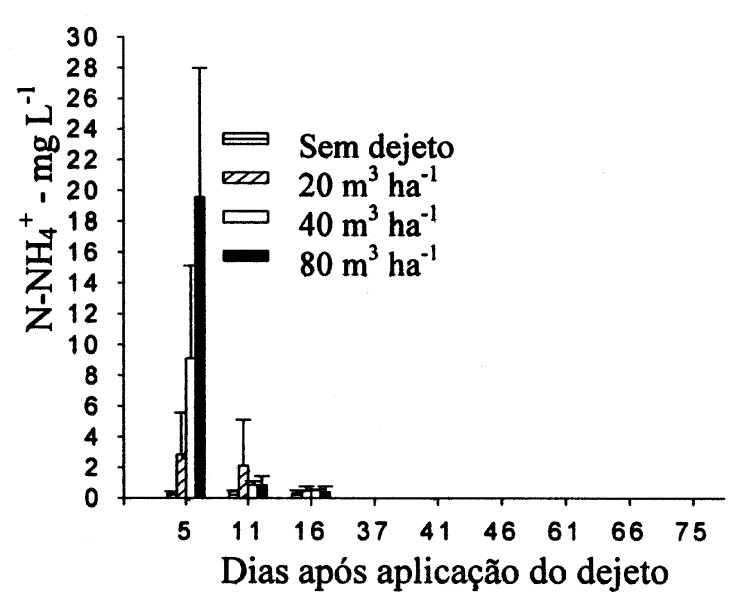

(b)

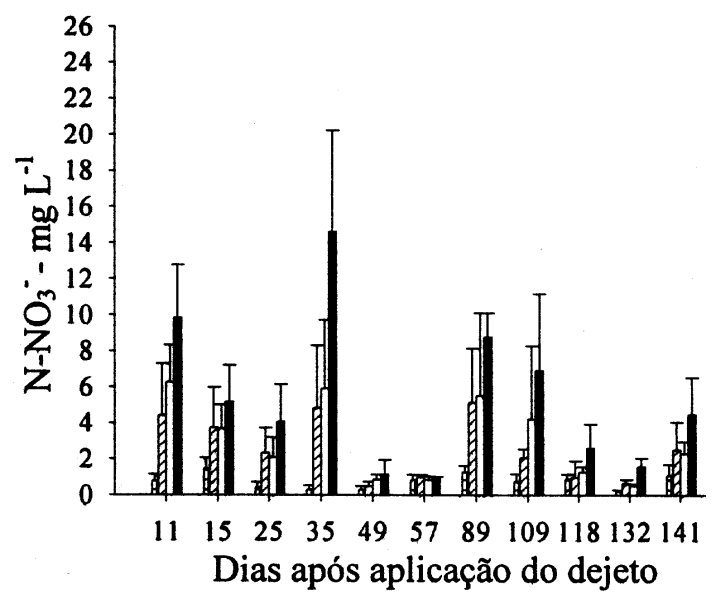

(d)

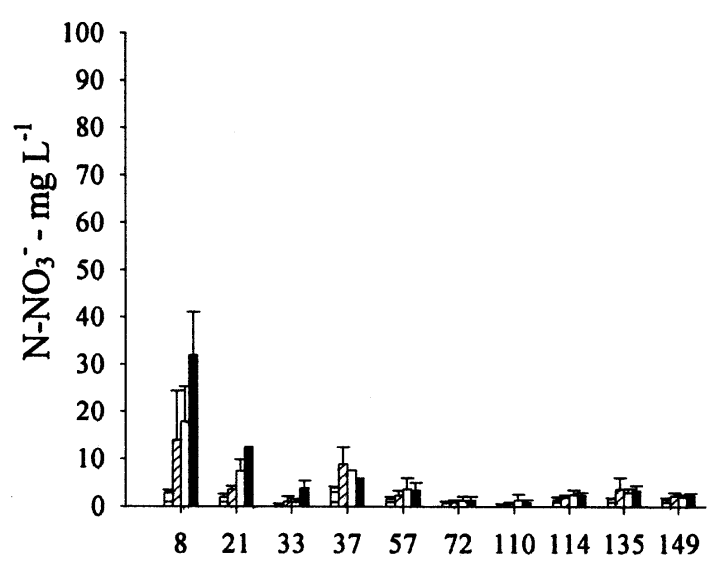

Dias após aplicação do dejeto

(f)

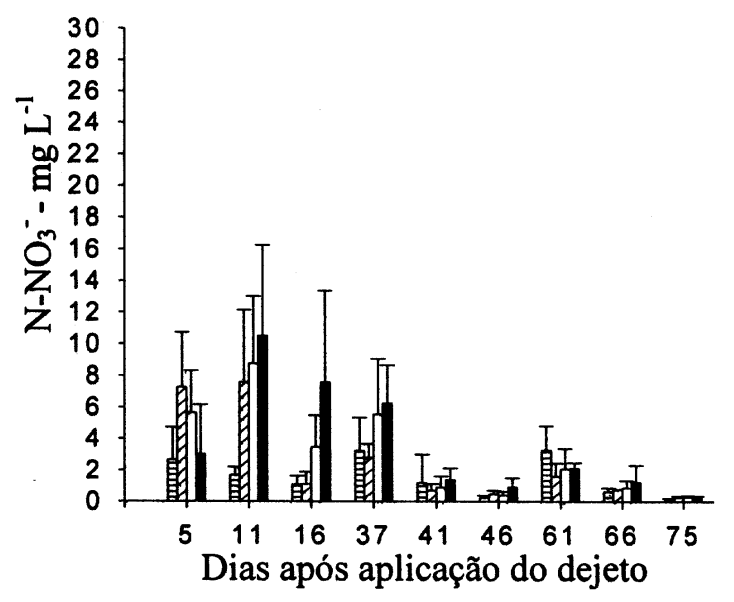

Figura 2 - Concentração de $\mathrm{N}\left(\mathrm{N}_{-} \mathrm{NH}_{4}^{+}\right.$e N-NO$\left.{ }_{3}^{-}\right)$na solução escoada na superfície do solo durante o cultivo da aveia preta no segundo ano (a) e (b), do milho (c) e (d) e nabo forrageiro (e) e (f), respectivamente, com aplicação de dejeto líquido de suínos.

Ciência Rural, v.35, n.6, nov-dez, 2005. 
o predomínio de $\mathrm{N}-\mathrm{NO}_{3}^{-}$sobre os teores de $\mathrm{N}-\mathrm{NH}_{4}^{+}$, já aos 8 dias após a aplicação do dejeto com um $\mathrm{pH}$ de 7,8, no segundo ano (Figura $2 \mathrm{~cd}$ ), pode ser a observação de SØRENSEN (1998), o qual cita que o incremento do $\mathrm{pH}$ do solo resultante da oxidação dos ácidos graxos voláteis presentes no dejeto, influencia o equilíbrio $\mathrm{NH}_{4}^{+} / \mathrm{NH}_{3}$ em favor do $\mathrm{N}-\mathrm{NH}_{3}$ um produto intermediário da transformação do $\mathrm{N}-\mathrm{NH}_{4}^{+}$para $\mathrm{N}-\mathrm{NO}_{3}^{-}$.

No primeiro ano de cultivo do nabo forrageiro e nos primeiros eventos, as concentrações de $\mathrm{N}_{-} \mathrm{NH}_{4}^{+}$e $\mathrm{N}-\mathrm{NO}_{3}^{-}$na solução escoada, nas três doses de dejeto, foram superiores às observadas no segundo ano (Figura $1 \mathrm{ef}$ ). Isso não se justifica, se considerado os baixos teores de matéria seca (0,8 e 1,2\%) dos dejetos aplicados antes da semeadura do nabo forrageiro nos dois anos, porém o efeito residual do nitrogênio orgânico do dejeto com quase $10 \%$ de matéria seca aplicado antes da semeadura do milho pode justificar em parte essa observação (Figura 1 cd).

Considerando o $\mathrm{N}$ total aplicado via dejeto e, determinando-se as perdas totais durante o primeiro ano, observa-se que as porcentagens de perdas foram maiores durante o cultivo da aveia preta, comparadas com o cultivo do milho e nabo forrageiro (Tabela 2). Esses maiores porcentuais nas perdas durante o cultivo da aveia podem ser devido as condições climáticas, já que durante esse período ocorrem as menores temperaturas do ano o que não favorece as perdas de nitrogênio por volatilização, além de uma maior umidade no solo, que pode favorecer o escoamento superficial.
Com o aumento da dose de dejeto as porcentagens de perdas de $\mathrm{N}$-total diminuíram com 40 e $80 \mathrm{~m}^{3}$ ha-1 e durante o cultivo do nabo forrageiro, sendo menores que as perdas na testemunha. Como o total de perdas de $\mathrm{N}$-total é resultado da concentração de $\mathrm{N}$ e do volume de águas escoadas, com o aumento da dose de dejeto se tem um incremento na produção de matéria seca das espécies da rotação e, conseqüentemente, aumento na absorção de $\mathrm{N}$ e uma diminuição no volume de água escoada. Isso foi observado durante o primeiro ano de cultivo do nabo forrageiro, onde o volume total de água perdida foi de 2140, 1509, 1120 e $521 \mathrm{~m}^{3} \mathrm{ha}^{-1}$, com as doses de 0, 20, 40 e $80 \mathrm{~m}^{3} \mathrm{ha}^{-1}$, respectivamente.

As concentrações de fósforo disponível representam a quantidade de $\mathrm{P}$ que, de fato tem relação direta com nutrição de plantas, porque foi extraído com HCl (Figura 3). Essas concentrações na solução escoada na superfície do solo foram maiores quanto mais próximo do dia da aplicação do dejeto ocorreram os escoamentos, à semelhança do observado para o nitrogênio (Figuras 1 e 2). Isso fica evidente quando se observa os teores de fósforo disponível no primeiro cultivo de aveia preta, quando houve uma redução de $84 \%$ nas concentrações de fósforo disponível da primeira (seis dias) para a segunda avaliação (dezoito dias) após a aplicação do dejeto (Figura 3a). Logo, no primeiro escoamento deve ter sido removido a maior parte do $\mathrm{P}$ solúvel que existia no dejeto quando da aplicação.

A porcentagem de matéria seca do dejeto aplicado e, por conseqüência, a quantidade de $\mathrm{P}$

Tabela 2 - Quantidade de nitrogênio total e fósforo total, aplicada via dejeto e suas perdas na solução escoada na superfície do solo durante o cultivo das três espécies da rotação, no primeiro ano agrícola (2000/01).

\begin{tabular}{|c|c|c|c|c|c|c|}
\hline \multirow{3}{*}{$\begin{array}{l}\begin{array}{l}\text { Doses de } \\
\text { dejeto }\end{array} \\
\left(\mathrm{m}^{3} \mathrm{ha}^{-1}\right)\end{array}$} & \multicolumn{3}{|c|}{ Quantidade aplicada $\left(\mathrm{kg} \mathrm{ha}^{-1}\right)$} & \multicolumn{3}{|c|}{ Quantidade perdida $\left(\mathrm{kg} \mathrm{ha}^{-1}\right)^{(1)}$} \\
\hline & \multicolumn{3}{|c|}{ Nitrogênio } & \multicolumn{3}{|c|}{ Nitrogênio } \\
\hline & Aveia & Milho & Nabo & Aveia & Milho & Nabo \\
\hline 0 & - & - & - & 2,5 & 9,6 & 5,6 \\
\hline 20 & 22 & 151 & 28 & $5,2(14)$ & $16,7(5,3)$ & $6,4(3,0)$ \\
\hline 40 & 44 & 301 & 56 & 6,8 (11) & $17,6(3,0)$ & $5,1^{(2)}$ \\
\hline \multirow[t]{2}{*}{80} & 88 & 602 & 112 & $9,8(9,4)$ & $14,6(1,0)$ & $3,9^{(2)}$ \\
\hline & \multicolumn{3}{|c|}{ Fósforo total } & \multicolumn{3}{|c|}{ Fósforo total } \\
\hline 0 & - & - & - & 1,2 & 2,0 & 1,3 \\
\hline 20 & 9,0 & 42,0 & 3,4 & $1,4(2,2)$ & $5,9(9,3)$ & $1,5(5,8)$ \\
\hline 40 & 18,0 & 84,0 & 6,8 & $1,6(2,2)$ & $7,0(6,0)$ & $1,4(1,5)$ \\
\hline 80 & 36,0 & 168,0 & 13,6 & $2,2(2,8)$ & $9,5(4,5)$ & 1,3 \\
\hline
\end{tabular}

(1) Os números entre parênteses representam as porcentagens das perdas em relação ao aplicado, considerando-se uma média de $50 \%$ do $\mathrm{N}$ total do dejeto na forma mineral e um potencial de perda desse $\mathrm{N}$ mineral por volatilização de 23,24 e 26 \% para as doses de 20 , 40 e $80 \mathrm{~m}^{3}$ ha $^{-1}$ respectivamente (BASSO et. al., 2004). Quanto ao fósforo, os números entre parênteses representam as perdas em relação ao P total aplicado via dejeto. Observar que no cálculo foi descontado o valor das perdas na testemunha.

${ }^{(2)}$ Um balanço negativo em relação a testemunha. 


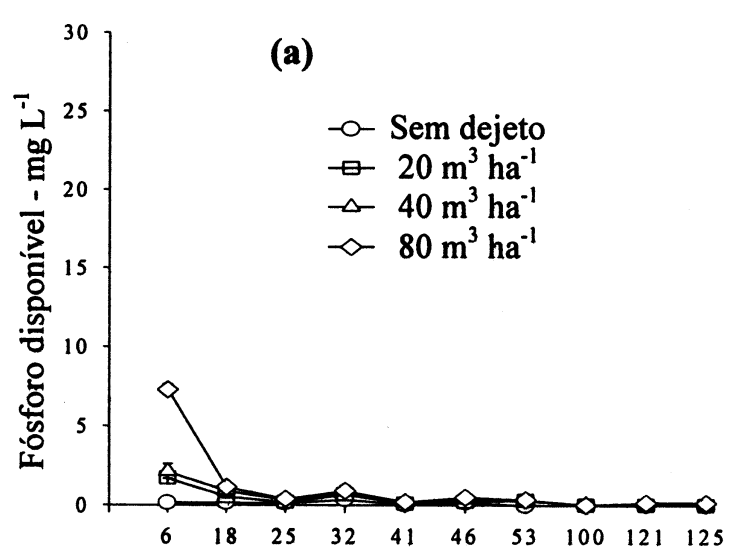

Dias após aplicação do dejeto

(c)

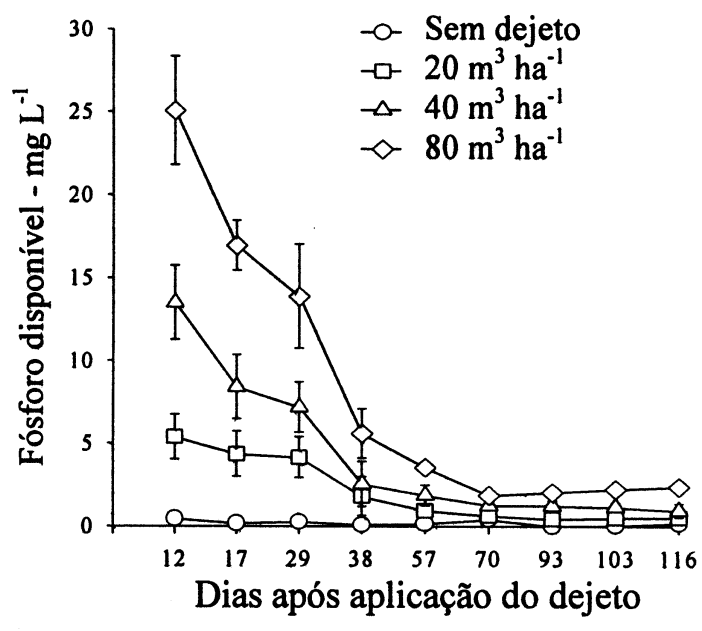

(e)

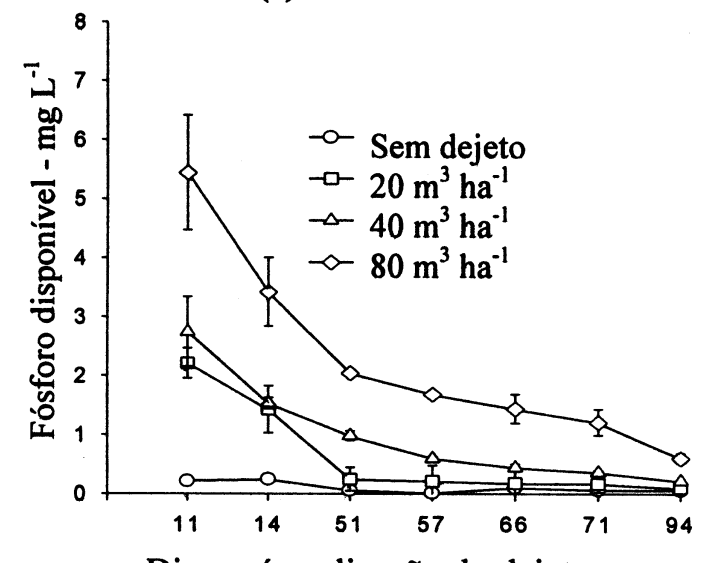

Dias após aplicação do dejeto

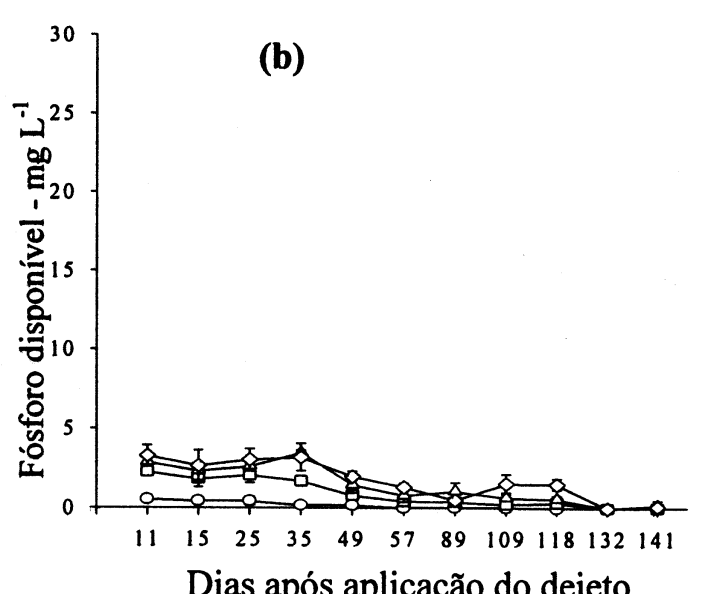

(d)

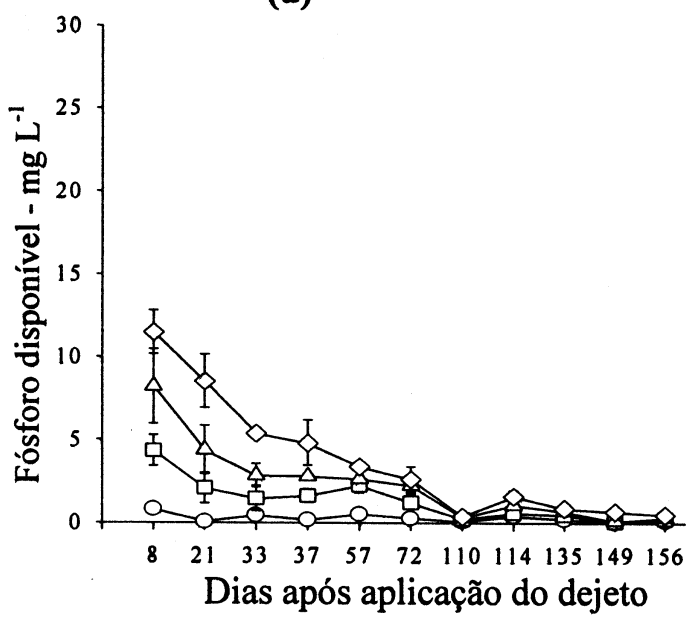

(f)

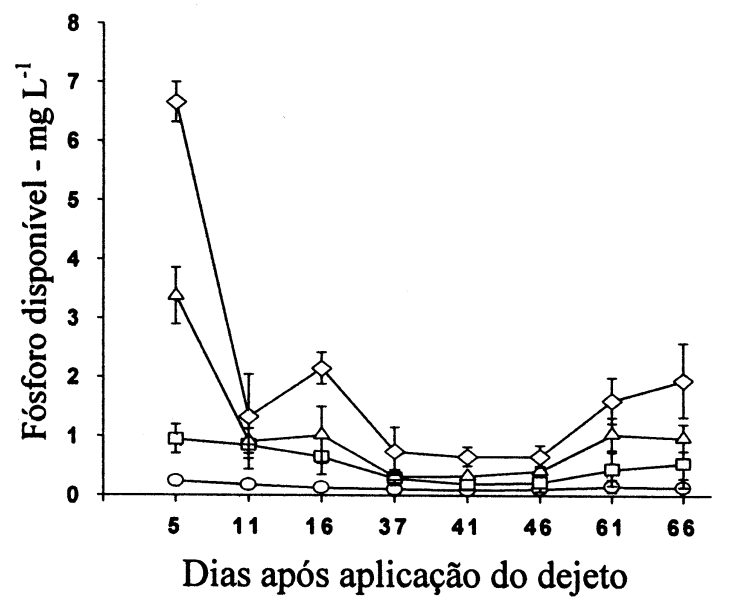

Figura 3 - Concentração de fósforo disponível na solução escoada durante o primeiro e segundo ano de cultivo da aveia preta (a) e (b) e do milho (c) e (d) e nabo forrageiro (e) e (f), respectivamente, com aplicação de dejeto líquido de suínos.

Ciência Rural, v.35, n.6, nov-dez, 2005. 
adicionada, também contribui para um maior ou menor incremento nas concentrações de fósforo disponível no solo, o que pode ser observado quando se compara as concentrações de fósforo na solução escoada na superfície do solo, nos dois anos de cultivo do milho (Figura 3cd). No primeiro ano, mesmo com o primeiro escoamento ocorrendo doze dias após a aplicação do dejeto, as concentrações de fósforo na solução escoada na superfície do solo foram em média duas vezes superiores às observadas para o segundo ano de cultivo do milho e que pode estar associado a quantidade de fósforo do dejeto aplicado antes da semeadura do milho no primeiro ano, em função de seu alto teor de matéria seca. Isso justifica também as maiores perdas ( $\mathrm{kg} \mathrm{ha}^{-1}$ ) quando comparado com o cultivo da aveia preta o do nabo forrageiro no primeiro ano agrícola (Tabela 1 ).

O somatório nas perdas de nitrogênio mineral na solução escoada na superfície do solo, nos dois anos da rotação aveia preta/milho/nabo forrageiro, foram muito pequenas no período de dois anos, levando-se em consideração a quantidade aplicada (Tabela 3). Observação semelhante mas com dejeto líquido de bovinos, foi feita por SMITH et al. (2001), depois de avaliar as perdas de nutrientes por escoamento superficial após aplicação do dejeto, tendo a concentração de nitrogênio solúvel variado de 2 a $14 \mathrm{mg} \mathrm{L}^{-1}$ para a dose de $80 \mathrm{~m}^{3} \mathrm{ha}^{-1}$. Para o autor, teores de $\mathrm{NH}_{4}^{+}$acima de $30 \mathrm{mg} \mathrm{L}^{-1}$ preocupam pelo potencial de eutroficação de águas. Por outro lado, maiores doses de dejeto também significarão maiores acúmulos de P na camada superficial do solo e isso ficou muito evidente no trabalho de CERETTA et al. (2003), num experimento de quatro anos onde foram feitas 28 aplicações sucessivas de dejeto de suínos em pastagem natural os teores de $\mathrm{P}$ disponível na superfície ficaram extremamente altos. Com isso, quanto maior o tempo de aplicações e quantidades de fósforo nos dejetos maior será o potencial de perdas de fósforo por escoamento, pela sua concentração na superfície.

As concentrações de $\mathrm{N}$ mineral na solução escoada na superfície do solo sugerem menores problemas quando da utilização de dejeto líquido de suínos com até $3 \%$ de matéria seca e uma aplicação de $40 \mathrm{~m}^{3}$ ha ${ }^{-1}$. Porém, com relação as concentrações de fósforo essas preocupam pelo seu potencial à eutroficação de águas, independentemente da dose de dejeto utilizada.

As perdas totais de fósforo disponível por escoamento superficial, durante os dois anos de condução do trabalho, foram 49, 21 e 20 vezes maiores do que as perdas por percolação com as doses de 20, 40 e $80 \mathrm{~m}^{3} \mathrm{ha}^{-1}$, respectivamente, conforme determinado nesse mesmo estudo por BASSO et al. (2005), evidenciando que o principal caminho de perdas do fósforo ocorre via escoamento superficial. Para o nitrogênio mineral, as perdas observadas nesse estudo foram apenas 4,0, 3,7 e 1,5 vezes maiores do que as observadas por percolação de nitrato, com as doses de 20, 40 e $80 \mathrm{~m}^{3} \mathrm{ha}^{-1}$, respectivamente, nesse mesmo estudo por BASSO et al. (2005).

A aplicação do dejeto em áreas mais declivosas deve ser encarada com muita cautela e, considerando-se que as maiores perdas estão relacionadas ao intervalo entre a aplicação do dejeto e o primeiro escoamento superficial, deve-se evitar a aplicação do dejeto quando há possibilidade eminente de chuva. É fundamental que em áreas onde é distribuído dejeto líquido de suínos exista a preocupação com a implantação de plantas de cobertura de solo, visando sistemas de rotação de culturas capazes de produzir e manter resíduos vegetais na superfície do solo, o que pode diminuir muito as perdas de nutrientes por escoamento superficial e, por conseqüência, o potencial poluente de dejetos líquidos de suínos.

Tabela 3 - Quantidade total de nitrogênio aplicado via dejeto e perdida na forma de $\mathrm{N}$ mineral $\left(\mathrm{NH}_{4}^{+}\right.$e $\left.\mathrm{NO}_{3}^{-}\right)$na solução escoada na superfície do solo nos dois anos da rotação aveia preta/milho/nabo forrageiro.

\begin{tabular}{|c|c|c|c|}
\hline \multirow{2}{*}{$\begin{array}{l}\text { Doses de dejeto } \\
\mathrm{m}^{3} \mathrm{ha}^{-1}\end{array}$} & \multirow{2}{*}{$\begin{array}{l}\text { Quantidade aplicada de nitrogênio em dois anos } \\
\text { nitrogênio total }\end{array}$} & \multicolumn{2}{|c|}{ Quantidade perdida de nitrogênio em dois anos } \\
\hline & & \multicolumn{2}{|c|}{ nitrogênio mineral } \\
\hline & $\mathrm{kg} \mathrm{ha}^{-1}$ & $\mathrm{~kg} \mathrm{ha}^{-1}$ & $\%$ \\
\hline 0 & - & 15 & - \\
\hline 20 & 293 & 38 & $8,9^{(1)}$ \\
\hline 40 & 585 & 32 & 3,3 \\
\hline 80 & 1170 & 36 & 2,1 \\
\hline
\end{tabular}

\footnotetext{
${ }^{(1)}$ Porcentagem de perda calculada considerando uma média de 50\% do $\mathrm{N}$ total do dejeto na forma mineral e um potencial de perda desse $\mathrm{N}$ mineral por volatilização de 23, 24 e $26 \%$ para as doses de 20, 40 e $80 \mathrm{~m}^{3}$ ha $^{-1}$ respectivamente (BASSO et. al., 2004). Observar que no cálculo foi descontado o valor das perdas na testemunha.
} 


\section{CONCLUSÕES}

As concentrações de fósforo disponível e nitrogênio mineral na solução escoada na superfície do solo foram diretamente relacionados com as doses de dejeto aplicadas. As concentrações de nitrogênio e fósforo na solução escoada na superfície do solo, bem como a predominância de amônio ou nitrato, estão diretamente relacionados à quantidade aplicada e ao intervalo entre a aplicação do dejeto e o primeiro escoamento superficial. As perdas de nitrogênio e fósforo por escoamento, do ponto de vista de nutrição de plantas, são pequenas, porém as concentrações observadas nos maiores picos preocupam pela possibilidade de eutroficação nos mananciais de água.

\section{AGRADECIMENTOS}

Parte da Tese de Doutorado em Agronomia do segundo autor. Programa de pós-graduação em Agronomia, Universidade Fedreal de Santa Maria (UFSM). Financiado pelo Conselho Nacional de Desenvolvimento Científico e Tecnológico (CNPq) e Conselho de Aperfeiçoamento de Pessoal de Ensino Superior (CAPES). Ceretta, bolsista do CNPq.

\section{REFERÊNCIAS}

ALMEIDA, A.C.R. Uso associado de dejeto líquido de suínos e plantas de cobertura de solo na cultura do milho. 2000, 114f. Dissertação (Mestrado em Agronomia) - Programa de Pós-graduação em Agronomia, Universidade Federal de Santa Maria.

BASSO, C.J. et al. Dejeto líquido de suínos: II - perdas de nitrogênio e fósforo por percolação no solo sob plantio direto. Ciência Rural, Santa Maria, v.35, n.6, p.12341242, 2005.

BASSO, C.J. et al. Perdas de nitrogênio de dejeto líquido de suínos por volatilização de amônia. Ciência Rural, Santa Maria, v.34, n.6, p.1775-1780, 2004.

BASSO, C.J. Perdas de nitrogênio e fósforo com aplicação no solo de dejetos líquidos de suínos. 2003. $125 \mathrm{f}$. Dissertação (Doutorado em Agronomia) - Programa de Pós- graduação em Agronomia, Universidade Federal de Santa Maria.

BERTOL, I. et al. Erosão hídrica em um Nitossolo Háplico submetido a diferentes sistemas de manejo sob chuva simulada. II-perdas de nutrientes e carbono orgânico. Rev Bras Ci Solo, Viçosa, v.28, p.10451054, 2004.

CERETTA, C.A. et al. Características químicas de solo sob aplicação de dejeto líquido de suínos em pastagem natural. Pesq Agropec Bras, Brasília, v.38, n.6, p.729-735, 2003.

EDWARDS, R.D.; DANIEL, C.T. Runoff quality impacts of swine manure applied to fescue plots. Amer Soc of Agric Engin, Michigan, v.36, n.2, p.81-86, 1993.

HEATHWAITE, L. et al. A conceptual approach for integrating phosphorus and nitrogen management at watershed scales. J Environ Qual, Madison, v.29, n.1, p.158-166, 2000.

MURPHY, J.; RILEY, J.P. A modified single solution method for determination of phosphate in natural waters. Anal Chem Acta, Oxford, v.27, n.1, p.3136, 1962 .

SHARPLEY, A.N. et al. Determining environmentally sound soil phosphorus levels. J Soil Water Conserv, Ankey, v.51, n.2, p.160-166, 1996.

SMITH, K. A. et al. Nutrient losses by surface run-off following the application of organic manures to arable land. 1. Nitrogen. Environ Pollution, Amesterdam, v.112, n.1, p.41-51, 2001.

SøRENSEN, P. Carbon mineralization, nitrogen immobilization and $\mathrm{pH}$ change in soil after adding volatile fatty acids. European J of Soil Sci, Dorchester, v.49, n.1, p.457-462, 1998.

STEENHUIS, S.F. et al. Winter-spread manure nitrogen losses. Amer Soc of Agric Engin, Michigan, v.24, n.3, p.436-449, 1981.

TEDESCO, M.J. et al. Análise de solo, plantas e outros materiais. Porto Alegre: Departamento de Solos, UFRGS, 1995. 174p.

YLI-HALLA, M. et al. Assessment of soluble phosphorus load in surface runoff by soil analyses. Agric Ecosyst Environ, Amesterdam, v.56, n.1, p.53-62, 1995.

YOUNG, R.A.; MUTCHLER, K.C. Polllution potencial of manure spread on frozen ground. J Environ Qual, Madison, v.5, n.3, p.174-181, 1976. 